\title{
DESIGN CONTEXTUALIZADO E BLENDED LEARNING COM METODOLOGIAS ATIVAS NA EDUCAÇÃO CORPORATIVA. CASO DE SUCESSO DE DESENVOLVIMENTO GERENCIAL EM UM TRIBUNAL ELEITORAL.
}

\author{
BRASÍLIA/DF MAIO/2018 \\ Joel Solon Farias de Azevedo - ProValore - joel@provalore.com.br \\ Tipo: Relato de Experiência Inovadora (EI) \\ Categoria: Métodos e Tecnologias \\ Setor Educacional: EDUCAÇÃO CORPORATIVA
}

\begin{abstract}
RESUMO
Caso de sucesso com programa de desenvolvimento gerencial em tribunal eleitoral. Programa bianual executado em 2017 e 2018, para desenvolvimento gerencial de 170 gestores, 85 em cada ano.

Planejamento prévio focado no design contextualizado na realidade da organização e nos problemas reais enfrentados pelos gestores.

Definição prévia dos objetivos de aprendizagem e produto final do curso, o acordo de trabalho/plano de contribuição da unidade do gestor para o ano seguinte, de forma alinhada à estratégia da organização. Aplicação de todos os princípios da aprendizagem de adultos da Andragogia de Malcolm Knowles. Execução da primeira parte do treinamento a distância com duração de quatro semanas e apoio do Moodle com foco construcionista provocado pela tutoria ativa e reflexiva.

Execução da segunda parte presencial com duração de apenas um dia para revisão e apresentação do trabalho final, o acordo de trabalho da unidade para o ano seguinte e resolução de todas as dúvidas a partir da discussão de cases de sucesso de organizações similares.
\end{abstract}

Palavras-chave: design contextualizado, blended learning, aprendizagem de adultos, metodologias ativas, construcionismo 


\section{Introdução}

As organizações precisam formar e desenvolver seus gestores, uma vez que na maioria das vezes não é possível contratar gestores $100 \%$ aptos a exercer cargos de liderança, sem pelo menos aculturá-los à realidade da organização.

Na organização pública a restrição é ainda maior, uma vez que a admissão por concurso prioriza as competências e o conhecimento técnico em detrimento das competências gerenciais.

Além disto, os programas clássicos de desenvolvimento gerencial baseados em estudos de casos de outras organizações não surtem o efeito desejado de criar o compromisso com a mudança.

Tais programas clássicos tem vários problemas detectados e que desagradam aos participantes:

1. No formato presencial, a necessidade de afastamento prolongado das atividades é malvista pela cultura de alta disponibilidade brasileira;

2. A possibilidade de afastamento prolongado agrava o medo de deixar o posto por muito tempo no comando do substituto, a ponto de a sua competência ser reconhecida como superior e se tornar uma ameaça ao titular do cargo;

3. No formato a distância perde-se a desculpa da baixa disponibilidade, mas correse o risco de tratamento superficial dos problemas a ponto de perder a oportunidade de realizar o desenvolvimento profissional no momento mais adequado;

4. A não contextualização na realidade premente e nos problemas reais combinada com a desculpa da baixa disponibilidade traz desinteresse e contribui diretamente para a evasão.

\section{Objetivos}

Os objetivos do programa de desenvolvimento gerencial são:

1. Realizar nivelamento e revisão conceitual de temas relacionados a tecnologias gerenciais para possibilitar o posterior aprofundamento e aperfeiçoamento e a implementação de práticas gerenciais;

2. Desenvolver e transferir metodologia gerencial no modelo de planejamento de resultados, focando as habilidades necessárias ao gestor para elaborar 
estratégias, atuar politicamente, tomar decisões, comunicar e negociar dentro de sua equipe e na organização, acompanhar o negociado e verificar o desempenho observado e sua relação com resultados esperados e os obtidos;

3. Entender a necessidade de estabelecer processos de planejamento de longo prazo e objetivos, indicadores, metas e mecanismos de acompanhamento do desempenho da gestão da organização e de suas unidades;

4. Gerenciar processos de negócio, de apoio e gerenciais e a sua contribuição para o alcance dos resultados da organização;

5. Gerenciar as pessoas e o desempenho das pessoas nos processos e projetos com foco no reconhecimento e na meritocracia.

\section{Referencial teórico}

A abordagem da educação corporativa baseia-se principalmente nos seis princípios fundamentais da aprendizagem de adultos de Malcolm Knowles, no livro The Adult Learner.

Knowles pontua assim os fatores críticos de sucesso da educação corporativa:

\section{A necessidade do aprendiz de saber}

Adultos não são curiosos como criança, e resistem naturalmente ao novo e à inovação enquanto não entenderem os objetivos da capacitação e a aplicação do novo conhecimento. Em outras palavras: - Por que eu preciso aprender isso? O que eu vou fazer com isso? Da mesma forma, o adulto tem a necessidade de saber o que vai ser abordado e como, é necessário que as regras sejam claras.

Com base neste princípio, aprendemos que não podemos simplesmente convocar as pessoas para capacitações com regras sigilosas. Não funciona. Nunca funcionou. A resistência será absurdamente grande.

É fator redutor do absenteísmo e presenteísmo a publicidade dos objetivos e informações básicas sobre a ação de aprendizagem, explicando bem o que e porque a pessoa precisa participar.

\section{Autoconceito do aprendiz}

Adultos, de regra, são mais autônomos e autodirigidos na busca do conhecimento. E tendem a perceber suas lacunas de conhecimento e buscar o que precisam para supri- 
las de forma independente. Esta premissa justifica a existência das trilhas de aprendizagem com a sinalização dos caminhos a serem percorridos, deixando para o agente a decisão e escolha dos objetos de aprendizagem mais adequados ao seu gosto.

\section{Experiência anterior do aprendiz}

Ao contrário das crianças, certo ou errado, o adulto já aprendeu. E convive com o dilema de desaprender para aprender novamente. $O$ adulto tem um modelo mental firmado com a sua percepção do mundo e de como as coisas funcionam. É o que chamamos de conceito anterior ou pré-conceito, que precisa ser entendido para ser substituído.

Neste sentido é crítico compreender a cultura organizacional e os modelos mentais incrustrados nas pessoas, de forma a associar os novos conhecimentos aos conhecimentos existentes.

\section{Prontidão para aprender}

Adulto aprende na necessidade. Quando precisa. Quando vê aplicação. No tempo certo.

É crítico que a oferta das ações de aprendizagem coincida com o momento da necessidade e a possibilidade de aplicação dos novos conhecimentos.

Por exemplo, uma formação técnica de gerente de projetos muito tempo antes do participante assumir o projeto tende a ser inócua. Ao contrário, uma mentoria efetiva de um profissional sênior desde antes e até depois do fim do projeto é uma ação muito mais efetiva.

\section{Orientação para aprendizagem}

Adultos tem a necessidade de conectar o aprendizado com a sua prática, com o seu dia a dia. Por isto aprendem muito mais de forma contextualizada na sua realidade diária, tratando de soluções viáveis e reais para problemas reais.

Aqui se faz crítico utilizar as metodologias ativas de problematização da realidade, aprendizagem baseada em projetos de intervenção e de mudança, sempre tomando como ponto de partida casos reais de sucesso e fracasso.

\section{Motivação para aprender}


No planejamento das ações de capacitação é preponderante explorar a motivação intrínseca do aprendiz adulto, que se interessa muito mais pelo reconhecimento obtido e autorrealização do que por outros fatores.

Neste sentido, estruturar níveis de certificação de competências pode ser muito mais interessante do que associar a remuneração ao desenvolvimento.

\section{Procedimentos metodológicos}

Aplicação sistemática das metodologias ativas de aprendizagem listadas no livro de João Mattar: Metodologias Ativas Para A Educação Presencial Blended e A Distância:

\section{Blended Learning}

2. Método de Caso

3. Aprendizagem baseada em Problemas

4. Aprendizagem baseada em Projetos

5. Aprendizagem baseada em Games e Gamificação

6. Sala de Aula Invertida

7. Peer Instruction

8. Design Thinking

9. Pesquisa

10. Dramatização

11. Avaliação por Pares e Autoavaliação

A problematização tem como ponto de partida o relato dos problemas enfrentados pelo participante no seu papel de gestor e a sugestão de prováveis soluções pelos seus pares.

Em seguida é realizado um diagnóstico organizacional com base em referencial externo, visando identificar o nível de maturidade gerencial da organização.

Ao mesmo tempo são publicados os resultados da autoavaliação da organização no levantamento de governança do Tribunal de Contas da União, que avalia diversos perfis de governança e gestão:

1. Perfil integrado de governança e gestão;

2. Perfil de governança pública;

3. Perfil de governança e gestão de pessoas;

4. Perfil de governança e gestão de TI 
5. Perfil de governança e gestão de contratações;

6. Perfil resultados.

Da comparação das avaliações resulta o entendimento do atual nível de maturidade gerencial da organização e a identificação de inúmeras oportunidades de melhoria, no nível da organização e das unidades.

O tutor, na sua atuação, se preocupa em não julgar o que é certo ou errado, mas apenas indicar as diversas alternativas de solução em função do contexto.

Ainda na fase a distância a grande maioria dos problemas relatados tem propostas viáveis de solução construídas coletivamente e juntamente com os pares, o que traz legitimidade.

O participante chega ao final do programa com a segurança necessária para propor as mudanças necessárias no nível da sua ingerência, já com a análise de viabilidade.

\section{Apresentação e discussão dos resultados}

O design contextualizado, combinado com a livre aplicação das metodologias ativas gera o interesse necessário ao aprendizado e à criação do conhecimento.

A abordagem aberta garante a autonomia requerida pelos adultos no papel de aprendiz.

A forte interação assíncrona na fase a distância com duração de quatro semanas garante o tempo necessário de maturação das ideias e propostas a ponto de resolver os dilemas internos e bloqueios e preconceitos do aprendiz.

A consequência é a garantia de compromisso com a mudança interna do aprendiz no seu papel de gestor e no compromisso para com a melhoria dos resultados da sua unidade, quantitativos e também qualitativos para a sua equipe, na forma de melhoria do clima organizacional.

O compromisso é tangibilizado na forma de proposta de acordo de trabalho/ plano de contribuição da unidade do gestor para o ano seguinte.

\section{Considerações finais}

A aplicação combinada do design contextualizado na realidade dos aprendizes com 
metodologias ativas reflexivas e o respeito aos princípios da aprendizagem de adultos garantiu o resultado esperado para o programa de desenvolvimento gerencial, tanto para a organização, tanto para os participantes.

\section{Referências}

The Adult Learner: The Definitive Classic in Adult Education and Human Resource Development (9781856178112): Malcolm S. Knowles Ph.D., Richard A. Swanson Ph.D., Elwood F. Holton III Ed.D.: Books.

MATTAR, João. Metodologias ativas para a educação presencial, blended e a distância. São Paulo: Artesanato Educacional, 2017. 